\title{
An Economic Dynamic Approach to the Infrastructure Commons
}

\author{
David M. Driesen
}

This Essay shows how combining Professor Frischmann's infrastructure commons concept with Economic Dynamic Theory can help analyze normative questions about how to manage commons resources that serve as infrastructure. Economic Dynamic Theory focuses on analyzing how various institutional choices can influence change over time.

This approach can work even when we cannot quantify many of the important benefits associated with infrastructure commons, such as its capacity to encourage future innovations or maintain healthy ecosystems. This Essay shows that sophisticated theorists, such as Lawrence Lessig, have tacitly applied this sort of analysis to infrastructure commons problems. Economic Dynamic Analysis provides a means of building on Professor Frischmann's insights to better manage the infrastructure commons.

Introduction

I. The Value of Considering Environmental Resources as Infrastructure

II. Infrastructure and Governance

III. Toward Economic Dynamic Analysis of the Management of the Infrastructure Commons

\section{INTRODUCTION}

The idea that environmental resources, like lakes, constitute infrastructure captures an important aspect of environmental resources' value to society. Indeed, environmental resources collectively constitute a life support system, providing an infrastructure not just for human beings, but for all forms of life. In this Essay I explore the infrastructure commons idea's potential to improve both environmental and intellectual property law. I find that its value for environmental law is very similar to the value Professor Lawrence Lessig

Copyright (C) 2008 by the Regents of the University of California.

University Professor, Syracuse University College of Law, ddriesen@law.syr.edu. 
ascribed to it for intellectual property law, as a valuable framing idea that may productively influence public policy. ${ }^{1}$ My aim here is to highlight extensions that may be needed to enable this idea to have the influence on public policy that it should have, emphasizing the need to focus on the economic dynamics of law in applying the idea to resource management decisions. ${ }^{2}$

\section{THE VALUE OF CONSIDERING ENVIRONMENTAL RESOURCES AS INFRASTRUCTURE}

As Professor Brett Frischmann recognizes, his infrastructure commons idea primarily influences the framing of resource management problems. ${ }^{3}$ This framing, as Frischmann suggests, has something in common with the movement within ecological economics to identify and value the "ecosystem services" that lakes and other environmental resources provide. ${ }^{4}$ The core of Frischmann's infrastructure definition highlights infrastructure's ability to provide an input into a wide variety of public and private goods. ${ }^{5}$ The ecosystem services idea involves looking at the value of some of the provided public goods. For example, wetlands provide water filtration and flood protection services. Economists can estimate the value of these services by observing the prices paid for water filtration plants and dikes. The infrastructure idea complements the ecosystem services approach by emphasizing the diversity and nature of these benefits, and therefore captures something important about why we need to protect environmental resources.

This framing is not a trivial gain. While Professor Frischmann gazing at Lake Michigan from a Chicago park bench may see infrastructure, some of Professor Carol Rose's neighbors in Arizona may see water, a rivalrous good that might not qualify as infrastructure. Viewing Lake Michigan as infrastructure may, as Professor Frischmann says, "allow[] us to appreciate the resource as part of a complex resource system."

Making Lake Michigan a "part of a complex resource system," however, may require an extension of the infrastructure idea to explicitly incorporate concepts of scale and networks, concepts familiar to intellectual property scholars. Lake Michigan by itself constitutes infrastructure. But Professor Frischmann's invocation of a more holistic vision suggests a new principle not

1. See Lawrence Lessig, Re-Marking the Progress in Frischmann, 89 MINN. L. Rev. 1031, 1034 (2005)

2. See generally David M. Driesen, The Economic Dynamics of Environmental LaW (2003); Symposium: Economic Dynamics of Environmental Law and Static Efficiency, 31 B.C. ENVTL. AFF. L. REV. 501-616 (2004).

3. See Brett M. Frischmann, An Economic Theory of Infrastructure and Commons Management, 89 MINN. L. REV. 917, 984 (2005) (claiming that "classifying a lake as infrastructure frames" the resource management problem in "broader fashion").

4. Id. at 988 (explaining that many environmental resources, including lakes, offer "ecosystem services").

5. Id. at 974 (characterizing infrastructure's generation of inputs into a wide variety of processes generating significant social benefits as the "key insights" from his analysis).

6. Id. at 990 . 
explicitly flagged in his scholarship - that we have to recognize the value of entire networks of resources. And to do this we must incorporate another principle, a demand that we view the network on the broadest possible scale. Otherwise, we may fail to appreciate even currently observable positive externalities associated with infrastructure.

\section{INFRASTRUCTURE AND GOVERNANCE}

I share Frischmann's concern that privatization of infrastructure may not work well, because important positive externalities do not produce appropriable gains. But why is that so? And would the government appreciate these positive externalities when private parties would not?

Professor Frischmann suggests that some services provided by "infrastructure resources" are "difficult to observe, much less appropriate." $\mathrm{He}$ emphasizes the appropriation problem in favoring common access solutions. But if a benefit is difficult to observe, then public resource managers may neglect it as well. He also states that markets will tend not to realize positive externalities when "they cannot be easily valued." 8 This raises a question about whether government adequately secures benefits that resist valuation. This problem of difficult to observe and quantify infrastructure benefits poses challenges for governments as well as for private actors that place some strain on any economic theory, even one as enlightened as the infrastructure commons theory.

Professor Frischmann's theory has implications not just for showing us where private markets might fail, but also for thinking about how to avoid government failure to adequately protect the values infrastructure commons provide. At a minimum, the theory implies that governments should not emulate markets. If government bases its actions only on quantitative costbenefit analysis, it, like private owners of infrastructure, will fail to take into account positive externalities that are difficult to observe and quantify.

This is a significant conclusion. In The Economic Dynamics of Environmental Law, I explained that most of government these days is based on two principles: privatize whenever possible, and rely on market emulation whenever privatization is not possible. ${ }^{9}$ The market emulation project includes heavy reliance on quantitative cost-benefit analysis to make fundamental decisions. ${ }^{10}$ Lawrence Lessig, in a similar vein, characterizes the instinctive reliance on private ordering as a key idea taken for granted in government decisionmaking. ${ }^{11}$ Recognition that managing infrastructure requires sensitivity

7. Id. at 981,988 .

8. Id. at 989 .

9. See DRIESEN, supra note 2 , at 2.

10. Id. at 1 .

11. See Lessig, supra note 1 , at 1031. 
to multiple, difficult to evaluate positive externalities calls this whole privatization project into question for an important category of resources.

Once we realize, however, that Frischmann's recognition of the importance of positive externalities that are difficult to detect and value calls cost-benefit analysis into question, we are left with a puzzle. How should government make infrastructure management decisions, such as decisions about how to address Internet and broadband access and how to manage a warming atmosphere?

\section{TOWARD ECONOMIC DYNAMIC ANALYSIS OF THE MANAGEMENT OF THE INFRASTRUCTURE COMMONS}

Frischmann's work suggests some emphasis on qualitative, not just quantitative analysis. He calls for a better understanding of how infrastructure resources create value for society because of their role in complex dynamic systems. ${ }^{12}$ And he calls for comparative institutional analysis. ${ }^{13}$ I agree with both of these points and propose an extension to move toward a more complete picture of what such an analysis might look like.

The comparative institutional analysis that Professor Frischmann calls for should consider prominently change over time. ${ }^{14}$ Even when we cannot quantify the most important costs and benefits of a change in a legal regime, we can evaluate the general direction of ongoing change in society. ${ }^{15}$ Economic Dynamic Theory explains the value of focusing on the direction of change over time and how it operates.

Economic Dynamic Theory calls for careful evaluation of the economic incentives that various regimes create in their institutional context. ${ }^{16}$ This implies noticing which incentives will most likely actually motivate key actors, not simply noting what incentives exist. ${ }^{17}$ Most actors respond to incentives through bounded rationality, paying attention only to the incentives and information that their habits and routines make salient. ${ }^{18}$ We can use this analysis of how economic incentives of competing regimes may influence change over time to predict the direction of changes over time and choose paths leading toward desirable sorts of change.

This sort of institutional analysis of legal regimes' impact on change over time, which I call Economic Dynamic Analysis, provides an alternative to a myopic focus on static efficiency, which matches supply and demand for a given technological state. ${ }^{19}$ Economic Dynamic Analysis instead emphasizes

12. See Frischmann, supra note 3 , at 1023 .

13. Id.

14. See DRIESEN, supra note 2, at 6 (stating that Economic Dynamics focuses upon change over time).

15. See id. at $7-8$.

16. See id. at 8.

17. See id.

18. See id.

19. Id. at 4 . 
careful thinking about the second pillar of law and economics, economic incentives, which almost everybody talks about, but which few legal scholars think about in a systematic way.

I demonstrated in The Economic Dynamics of Environmental Law how these ideas might reshape thinking about environmental law and about regulated industry. ${ }^{20}$ The book shows, for example, how Economic Dynamic Analysis can help us address issues raised by the Telecommunications Act of 1996. I show how this analysis highlights and helps us think about the issue of whether the policy of universal service, which remained entrenched in the Act, can survive the competition-based regime that constitutes the Act's centerpiece. $^{21}$

The idea of Economic Dynamic Analysis describes the deep structure of what many perceptive legal analysts do. For example, Professor Lessig in The Future of Ideas implicitly relies on an Economic Dynamic Analysis grounded in the concept of bounded rationality to argue for an open infrastructure commons (in Frischmann's terms). ${ }^{22}$ Proponents of the idea of bounded rationality, an important antidote to theories based on perfect information, claim that economic actors cannot possibly process all available information and therefore rely on rules of thumb to ferret out the limited information they will pay attention to. Because of this screening, understanding the precise limits of bounded rationality for a particular individual or institution can help predict various economic incentives' effects and hence guide choices about institutional arrangements.

Lessig implicitly invokes bounded rationality when he notes that the founders of the Internet could not know what sort of innovations it might spawn. ${ }^{23}$ This bound upon rationality makes optimization of the net for particular applications a poor choice. Because the Internet's founders could not intelligently optimize the net for innovations they could not identify, they relied on a "dumb" end-to-end design, which makes it easy for end-users to use the commons of the net as an innovation platform. ${ }^{24}$

20. See id.

21. See id. at 206-07.

22. See Lawrence Lessig, The Future of IDEAS: The fate of the Commons in a CONNECTED WORLD 88-89(2001).

23. Id. at 88 .

24. Id. at 88-89. The principle of "dumb" end-to-end design informs the design of protocols for the transmission of data through the internet. Marjory S. Blumenthal \& David D. Clark, Rethinking the Design of the Internet: The End-to-End Arguments vs. the Brave New World, 1 ACM TRANSACTIONS ON INTERNET TECH. 70, 70 (2001) (describing the "end-to-end" argument as a design principle that has been employed in creating the internet). The idea favors making central elements of a network extremely simple, i.e. dumb, and having more complicated elements of data transfer protocols be executed at the terminals on the network's periphery. See LESSIG, supra note 22, at 34 (describing "end-to-end" design as putting intelligence at the network ends, leaving the network itself simple); J.H. Saltzer et al., End-toEnd Arguments in System Design, 2 ACM TRANSACTIONS ON COMPUTER SYSTEMS 277 (1984), available at http://web.mit.edu/Saltzer/www/publications/endtoend/endtoend.pdf. 
Lessig then uses, apparently unconsciously, the notion of path dependency, another pillar of Economic Dynamic Theory, ${ }^{25}$ to further his argument. Building (as I do as well) on the work of Clay Christensen, the author of The Innovator's Dilemma, ${ }^{26}$ he shows how path dependency limits the innovation capacity of established companies. He shows that companies tend to become expert in refining the technologies they know and serve the markets they have helped create, but can easily miss opportunities for innovation that would disrupt these markets. ${ }^{27} \mathrm{He}$ fears that established firms' path-dependent bounded rationality and the economic incentive they have to discourage disruptive technology can lead to the squashing of innovation. ${ }^{28}$ Therefore, he suggests, leaving the infrastructure commons of the net open might be a very good idea. ${ }^{29}$ When we have little understanding of how a resource might be used, we should favor disruption by leaving it in the commons, says Lessig. ${ }^{30}$

Lessig's idea closely tracks another pillar of Economic Dynamic Analysis, Douglas North's idea of adaptive efficiency. ${ }^{31}$ When we cannot sum relevant costs and benefits, North explains, we should choose the option that maximizes our future flexibility - our ability to grow and experiment. ${ }^{32}$ This choice of an option maximizing future flexibility maximizes our ability to adapt, and therefore is adaptively efficient. Lessig does exactly what the Economic Dynamic Theory recommends; he analyzes economic incentives based on bounded rationality and path dependence to predict the shape of change over time as a guide to optimal policy, using a concept of adaptive efficiency that works even when we cannot quantify salient benefits. ${ }^{33}$

Lessig's comment on Frischmann's theory invites more work on the question of how to "measure" the benefits of open access. ${ }^{34}$ Lessig characterizes his own defense of open access in The Fate of Ideas as only identifying some factors that are relevant to decisions about an open access commons, rather than comprehensively measuring the costs and benefits of open access. ${ }^{35}$ In fact, Frischmann's work can, together with Economic Dynamic Analysis, contribute to measuring the benefits of open access, provided that the idea of measurement is understood in a limited way.

25. See DRIESEN, supra note 2, at 7.

26. Clayton Christensen, The InNovator's Dilemma; When New Technologies Cause GREAT FIRMS TO FAIL (1997); see also DRIESEN, supra note 2, at 109-10 (citing Christensen to support the idea that firms can fail if they "forgo innovation in favor of the status quo").

27. See LESSIG, supra note 22, at 89-91.

28. Id. at $91-92$.

29. Id. at 92 .

30. Id. at 88-92.

31. See DRIESEN, supra note 2, at 7.

32. $I d$.

33. Id. at 4-5.

34. See Lessig, supra note 1 , at 1039.

35. Id. at 1039 n.15. 
We must first, however, appreciate what "measurement" must mean in the infrastructure commons context. It cannot mean "to quantify." We need to use an Economic Dynamic Theory and the insights of the infrastructure commons idea to reject the notion that quantification offers an acceptable, even-handed way to measure benefits. The wide variety of benefits that an infrastructure commons provides suggests that government, which has limited capacity, cannot quantify them all, even if quantification is possible. But we cannot quantify the benefits of innovations that we cannot even identify, or of ecological systems that we only partially understand. Soft variables, like those associated with environmental quality or the communitarian values of the net, tend to get lost in such a calculus. We can, however, predict the shape of change over time using Economic Dynamic Analysis.

Measurement must involve the construction of a vision of a positive economic and social dynamic over time. Evaluating comparative institutional arrangements does require the consideration of both the advantages and disadvantages of possible architectures. But framing these advantages as costs and benefits suggests, wrongly, that quantification can neutrally evaluate these futures. I argued in The Economic Dynamics of Environmental Law that the static efficiency that quantitative economic analysis usually aims to achieve, while certainly desirable, is not the key value the public sees in markets. The public values innovation and economic growth, and there is a debate in the economics literature about whether economic growth and perfect static efficiency are compatible. ${ }^{36}$

Economic Dynamic Analysis of law provides a useful framework for analysis. It may be a prerequisite to measuring the benefits of open access, but it does not, by itself, measure the benefit of any infrastructure commons. The infrastructure commons idea, however, suggests some fruitful paths for further work that can better evaluate these benefits using the Economic Dynamic approach. In particular, Professor Frischmann's definition of infrastructure highlights not just the variety of benefits infrastructure delivers, but important aspects of their nature. He emphasizes that such a commons is, at least partially, nonrivalrous. So, for example, my use of Frischmann's ideas in this Essay does not in any way limit his use of his ideas. Indeed, it may, I can earnestly hope, help him use his ideas better. If I went over and took his cup of coffee, that would constitute a rivalrous use, as he could no longer drink his cup of coffee. This suggests that the infrastructure commons, as a supplier of nonrivalrous goods, can have a multiplier effect not present with rivalrous goods. We can get further by noticing that in many contexts some uses of an infrastructure commons are rivalrous, while others are not. For example, when I breathe, I do not limit your use of the air. When a coal-fired power plant spews fine particulate into the atmosphere, it does limit the extent to which you can safely breathe. This suggests that a comparative institutional analysis might

36. See DRIESEN, supra note 2, at 4-5. 
evaluate which uses of an infrastructure commons have multiplier effects (ideas), which do not create scarcity (breathing), and which do create scarcity (pollution).

We can use this analysis of the nature of infrastructure uses to evaluate the benefits of open access or access limits when combined with an Economic Dynamic Analysis showing how different commons' uses influence incentives. For example, some uses of the Internet, such as spam and viruses, are rivalrous in the sense that they impede other uses of the net. We can ask whether over time an open commons would lead these uses to seriously diminish the positive values of the resource. If so, we would need to at least evaluate whether an endto-end design is compatible with effectively limiting these rivalrous uses that have the capacity to destroy, or at least seriously limit, the commons'capacity to deliver benefits.

Another idea from The Economic Dynamics of Environmental Law might also build on the Frischmann framework, the idea that Economic Dynamic Analysis should consider whom particular architecture empowers. ${ }^{37}$ The Internet that Professor Lessig so admires served a relatively small, albeit rapidly growing, community. Enabling the larger community to use the Internet requires capacity increases over time. An Economic Dynamic Analysis must address the question of whether funding this capacity increase is consistent with open access. One must evaluate whether the bounded rationality of those in a position to add bandwidth will cause them to desist unless they gain some measure of control over the architecture. ${ }^{38}$ If they would desist absent some control, then Economic Dynamic Analysis can only support open access if a case is made for some alternative way of building capacity or for the idea that additional capacity is not needed. The net could remain formally open without added capacity if it serves only a narrow community, such as academics and researchers. But this approach would require a justification. Much more can be said about this, but I suspect it would be better said by intellectual property experts like Lessig and Frischmann. I hope I've said enough to show that the infrastructure commons concept has the potential to further the Economic Dynamic Analysis of law as a method for evaluating institutional choice.

\section{CONCLUSION}

The idea of the infrastructure commons constitutes an important contribution to our thinking about the value of both environmental and intellectual resources. Extensions of this idea that build on the concept of the economic dynamics of law have significant potential to strengthen analysis of how to properly manage resources that can serve as an infrastructure commons.

37. Id. at 8 .

38. See LESSIG, supra note 22, at 156-58 (listing examples of cable companies' efforts to limit access and use through control of Internet "architecture"). 